\title{
miR-200b regulates breast cancer cell proliferation and invasion by targeting radixin
}

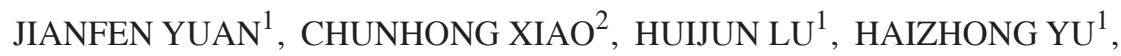 \\ HONG HONG ${ }^{1}$, CHUNYAN GUO ${ }^{1}$ and ZHIMEI WU ${ }^{1}$ \\ ${ }^{1}$ Department of Clinical Laboratory, Nantong Traditional Chinese Medicine Hospital, Nantong, Jiangsu 226001; \\ ${ }^{2}$ Department of Clinical Laboratory, Nantong Tumor Hospital, Nantong, Jiangsu 226361, P.R. China
}

Received December 7, 2018; Accepted October 15, 2019

DOI: $10.3892 /$ etm.2020.8516

\begin{abstract}
Radixin is an important member of the Ezrin-Radixin-Moesin protein family that is involved in cell invasion, metastasis and movement. microRNA (miR)-200b is a well-studied microRNA associated with the development of multiple tumors. Previous bioinformatics analysis has demonstrated that miR-200b has a complementary binding site in the 3'-untranslated region of radixin mRNA. The present study aimed to investigate the role of miR-200b in regulating radixin expression, cell proliferation and invasion in breast cancer. Breast cancer tissues at different Tumor-Node-Metastasis (TNM) stages were collected; breast tissues from patients with hyperplasia were used as a control. miR-200b and radixin mRNA expression levels were tested by reverse transcription-quantitative PCR. Radixin protein expression was detected by western blotting. The highly metastatic MDA-MB-231 cells were divided into four groups and transfected with a miR-negative control (NC), miR-200b mimic, small interfering (si)RNA-NC or siRNA targeting radixin. Cell invasion was evaluated by Transwell assay and cell proliferation was assessed by 5-ethynyl-2'-deoxyuridine staining. Compared with the control group, radixin mRNA expression was significantly higher in breast cancer tissues and increased with TNM stage. miR-200b expression levels exhibited the opposite trend. Radixin mRNA expression in breast cancer cells was notably higher, whereas miR-200b expression was lower compared with that in normal breast epithelial MCF-10A cells. The expression of radixin was higher, whereas
\end{abstract}

Correspondence to: Dr Chunhong Xiao, Department of Clinical Laboratory, Nantong Tumor Hospital, 30 Tong Yang North Road, Nantong, Jiangsu 226361, P.R. China

E-mail: luan93799353@163.com

Dr Haizhong Yu, Department of Clinical Laboratory, Nantong Traditional Chinese Medicine Hospital, 41 Construction Road, Nantong, Jiangsu 226001, P.R. China

E-mail: vxxnpdbvzdnfl@sina.com

Key words: microRNA-200b, radixin, breast cancer, proliferation, invasion
miR-200b was lower in MDA-MB-231 cells compared with that in MCF-7 cells. miR-200b mimic or siRNA-radixin transfection downregulated the expression of radixin in MDA-MB-231 cells and attenuated the invasive and proliferative abilities of these cells. miR-200b-knockdown and radixin overexpression were associated with enhanced cell invasion in breast cancer. In conclusion, miR-200b regulates breast cancer cell proliferation and invasion by targeting radixin expression.

\section{Introduction}

Breast cancer (BC) is one of the most common malignant tumors among women in the world that seriously threaten women's health and quality of life (1-3). In recent years, with the development of economy and the change of lifestyle, the incidence of female BC in China has increased, and a trend for younger age at diagnosis has emerged (4-6). The occurrence of the majority of malignant tumors is associated with abnormal changes in certain key genes, such as inactivation of tumor suppressor genes, activation of oncogenes and abnormal expression of certain apoptosis- or proliferation-associated proteins $(7,8)$. These changes lead to abnormal cell proliferation, apoptosis and differentiation. At present, there are numerous studies that have focused on the pathogenesis of $\mathrm{BC}$, while its specific mechanism remains unclear.

Ezrin-radixin-moesin (ERM) proteins are mainly distributed on the surface of actin-rich cells and participate in the regulation of cell proliferation, differentiation, adhesion and movement; they serve an important role in maintaining cytoplasmic stability and cell membrane structure (9-11). ERM proteins participate in the development of malignant tumors and serve a key role in tumor invasion and metastasis through cytoskeleton and cell signal transduction $(9,10,12)$. Radixin is an important member of the ERM protein family involved in the invasion, and migration of tumor cells (13-15). Compared with ezrin and moesin, a limited number of studies have focused on the role of radixin in tumor development.

microRNA (miR or miRNA) is an endogenous single-stranded small non-coding RNA, 18-25 nucleotides in length. miRNAs can bind to the 3'-untranslated region (UTR) of their target gene mRNAs to affect the stability of the mRNA, resulting in complete degradation or protein translation inhibition and negatively regulating gene expression 
at the post-transcriptional level (16). Numerous studies have demonstrated that the abnormal expression of miRNAs serves tumor-promoting or suppressing roles in the pathogenesis of malignant tumors and can affect tumor invasion and metastasis by regulating the expression of key genes (17-19). miR-200b is closely associated with the occurrence and progression of multiple types of tumors, including prostate, non-small cell lung or cervical cancer (20-22). Bioinformatics analysis has revealed that miR-200b has a complementary binding in the 3'-UTR of radixin mRNA, indicating a possible regulatory relationship. The present study aimed to investigate the role of $\mathrm{miR}-200 \mathrm{~b}$ in the regulation of radixin expression, cell proliferation and invasion in $\mathrm{BC}$.

\section{Materials and methods}

Reagents and materials. The human normal breast cell line MCF-10A, moderately metastatic BC cell line MCF-7 and highly metastatic BC cell line MDA-MB-231 were purchased from the Cell Bank of Type Culture Collection of the Chinese Academy of Sciences. DMEM and fetal bovine serum (FBS) were purchased from Gibco; Thermo Fisher Scientific, Inc. TRIzol ${ }^{\circledR}$ was purchased from Invitrogen; Thermo Fisher Scientific, Inc. TransScript ${ }^{\circledR}$ First-Strand cDNA Synthesis SuperMix was purchased from Beijing Transgen Biotech Co., Ltd. miR-negative control (NC) (5'-UUCUCCGAACGU GUCACGUTT-3'), miR-200b mimic (5'-UAAUACUGCCUG GUAAUGAUGA-3'), miR-200b inhibitor (5'-UCAUCAUUA CCAGGCAGUAUUA-3') and miR-200b NC inhibitor control (5'-UUCUCCGAACGUGUCACGUTT-3') and riboFECT ${ }^{\mathrm{TM}}$ $\mathrm{CP}$ transfection reagent were purchased from Guangzhou RiboBio Co., Ltd. Rabbit anti-human N-cadherin (cat. no. 4061) and E-cadherin (cat. no. 3195) antibodies were purchased from Cell Signaling Technology, Inc. Rabbit anti-human $\beta$-actin (cat. no. ab16039) and radixin (cat. no. ab227266) antibodies were purchased from Abcam. Horseradish peroxidase (HRP)-conjugated goat anti-Rabbit IgG $(\mathrm{H}+\mathrm{L})$ secondary antibody (cat. no. 31460) was purchased from Thermo Fisher Scientific, Inc. The Transwell chamber was purchased from EMD Millipore. Matrigel was obtained from BD Biosciences. Dual-Luciferase assay kit was purchased from Promega Corporation. pMIR luciferase reporter plasmid was purchased from Shaanxi Youbio Technology Co., Ltd.

Clinical information. A total of 36 patients with BC aged between 41 and 71 years (mean age, $53.69 \pm 14.59$ years) were treated at Nantong Traditional Chinese Medicine Hospital (Nantong, China) between January and December 2017 were recruited for this study. All patients were diagnosed by pathological examination and did not receive radiotherapy or chemotherapy prior to the surgery. A total of 12 cases of stage II, 14 cases of stage III and 10 cases of stage IV were diagnosed. In addition, 14 cases aged between 39 and 70 years (mean age, $52.03 \pm 10.91$ years) of normal breast tissue with mammary gland hyperplasia were recruited at the same hospital during the same time period as a control group.

The study was approved by the Research Ethics Committee of Nantong Traditional Chinese Medicine Hospital, and all patients provided written informed consent prior to the study.
Cell culture. MCF-10A, MCF-7 and MDA-MB-231 cells were maintained in DMEM containing $10 \% \mathrm{FBS}$ and $1 \%$ penicillin/streptomycin (Thermo Fisher Scientific, Inc.) and cultured in an incubator at $37^{\circ} \mathrm{C}$ with $5 \% \mathrm{CO}_{2}$. The cells were passaged every 3-4 days.

Dual luciferase reporter gene assay. The PCR product of the radixin 3'-UTR full-length fragment was amplified from MCF-7 cells (Primer sequences: Forward, 5'-AGCTGAACC ACCAACAGAGAA-3' and reverse, 5'-TGGAAAAGAGGC AATGGAAC-3') using the Titanium ${ }^{\circledR}$ Taq PCR Kit according to manufacturer's protocol (Clontech Laboratories, Inc.). The thermocycling conditions were as follows: Initial denaturation at $94^{\circ} \mathrm{C}$ for $5 \mathrm{~min}$, followed by $25-30$ cycles of denaturation at $94^{\circ} \mathrm{C}$ for $30 \mathrm{sec}$, annealing at $55^{\circ} \mathrm{C}$ for $30 \mathrm{sec}$ and extension at $72^{\circ} \mathrm{C}$ for $30 \mathrm{sec}$, with a final extension step at $72^{\circ} \mathrm{C}$ for $10 \mathrm{~min}$. The PCR production was then double-digested by HindIII and $M l u \mathrm{I}$ and ligated into the pMIR plasmid. Following connection by T4 DNA ligase, the plasmid was transformed into DH5 $\alpha$-competent E. coli cells (Thermo Fisher Scientific, Inc.) to screen a positive clone. Following sequencing, pMIR-Radixin-wild-type (wt) and pMIR-Radixin-mutant (mut) plasmids were selected. 293T cells (Thermo Fisher Scientific, Inc.) were transfected with $1 \mu \mathrm{g}$ pMIR-Radixin-wt or pMIR-Radixin-mut with the miR-200b mimic, inhibitor or NC using riboFECT ${ }^{\mathrm{TM}} \mathrm{CP}$ transfection reagent. Following incubation for $48 \mathrm{~h}$, luciferase activity was detected using a Dual-Luciferase assay kit according to the manufacturer's protocol. All luciferase activities were normalized to that of Renilla luciferase.

Manipulation of miR-200b expression in MDA-MB-231 cells. MDA-MB-231 cells were divided into two groups, inoculated into $10-\mathrm{cm}$ culture dishes and cultured to $50-60 \%$ confluency, followed by transfection with miR-NC or miR-200b mimic. A total of $5 \mathrm{nM}$ miR-NC-mimic or miR-200b mimic and miR-NC-inhibitor or miR-200b inhibitor were diluted in $100 \mu 1$ riboFECT ${ }^{\mathrm{TM}} \mathrm{CP}$ Buffer at room temperature for $5 \mathrm{~min}$ and incubated with $10 \mu \mathrm{l}$ riboFECT ${ }^{\mathrm{TM}} \mathrm{CP}$ Reagent at room temperature for $0-15 \mathrm{~min}$. The mixture was added to the cell culture medium and incubated for $72 \mathrm{~h}$ at $37^{\circ} \mathrm{C}$ prior to further experiments.

Radixin siRNA transfection. MDA-MB-231 cells were divided into two groups, inoculated into $10-\mathrm{cm}$ culture dishes and cultured to 50-60\% confluency, followed by transfection with siRNA-NC or siRNA-radixin. The transfection protocol was the same as that aforementioned.

Reverse transcription-quantitative PCR (RT-qPCR). Total RNA was extracted from MDA-MB-231 cells using the miRNeasy FFPE kit (Qiagen China Co., Ltd.). TransScript ${ }^{\circledR}$ Green One-Step qRT-PCR SuperMix (Beijing Transgen Biotech Co., Ltd.) was used for one step RT-qPCR detection. The PCR system comprised $1 \mu \mathrm{g}$ template RNA, $0.3 \mu \mathrm{M}$ forward and reverse primers, $10 \mu \mathrm{l} 2 \mathrm{X}$ TransStart Tip Green qPCR SuperMix, $0.4 \mu$ l One-Step RT Enzyme mix and $0.4 \mu 1$ Passive Reference Dye II dissolved in RNase-free water. The reaction was performed on an $\mathrm{ABI} \mathrm{ViiA}^{\mathrm{TM}} 7 \mathrm{PCR}$ system at $94^{\circ} \mathrm{C}$ for $5 \mathrm{~min}$, followed by 40 cycles of $94^{\circ} \mathrm{C}$ for $5 \mathrm{sec}$ and 
$60^{\circ} \mathrm{C}$ for $30 \mathrm{sec}$. U6 and GAPDH was used as reference genes for miRNA and mRNA expression, respectively. Quantitative analysis was performed using the $2^{-\Delta \Delta \mathrm{Cq}}$ method (23). Primer sequences used for RT-qPCR were as follows: Radixin forward, 5'-CTCGAAAAGCTCTAGAACTGG-3' and reverse, 5'-GGT TCATTACCCCTTCATTTG-3'; miR-200b forward, 5'-ACA GTAATACTGCCTGGTAATG-3' and reverse, 5'-GGTCCA GTTTTTTTTTTTTTTTCATC-3'; U6 forward, 5'-CTCGCT TCGGCAGCACA-3' and reverse, 5'-ACGCTTCACGAATTT GCGT-3'; GAPDH forward, 5'-CAGCGACACCCACTCCTC CACCTT-3' and reverse, 5'-CATGAGGTCCACCACCCT GTTGCT-3'.

Western blotting. Total protein was extracted from MDA-MB-231 cells by SDS lysis and quantified by the BCA method. A total of $40 \mu \mathrm{g}$ protein/lane was separated by 8-10\% SDS-PAGE and transferred to a PVDF membrane at $300 \mathrm{~mA}$ for $1.5 \mathrm{~h}$. Following blocking by $5 \%$ skimmed milk at room temperature for $6 \mathrm{~h}$, the membrane was incubated with primary antibodies at $4^{\circ} \mathrm{C}$ overnight ( $\mathrm{N}$-cadherin, 1:2,000; E-cadherin, 1:2,000; radixin, 1:1,000; and $\beta$-actin, 1:10,000). The membrane was washed with PBST and further incubated with the HRP-conjugated secondary antibody $(1: 10,000)$ at room temperature for $60 \mathrm{~min}$. Finally, the membrane was treated with ECL chemiluminescence reagent and developed. Image J software 1.52 (National Institutes of Health) was used for densitometric analysis of band intensity.

Flow cytometry. MDA-MB-231 Cells $\left(1 \times 10^{6} / \mathrm{ml}\right)$ were treated with $10 \mu \mathrm{M}$ 5-ethynyl-2'-deoxyuridine (EdU) solution in the logarithmic phase. Following 48-h incubation, the cells were digested with trypsin, collected, stained with Alexa Fluor-488 labeled reaction liquid (cat. no. C10337; Thermo Fisher Scientific, Inc.) at room temperature for $30 \mathrm{~min}$ and detected using a Beckman Coulter FC 500 MCL/MPL flow cytometer (Becton, Dickinson and Company). FlowJo software (version 7.6.1; FlowJo LLC) was used for the analysis of results.

Cell Counting Kit-8 (CCK-8) assay. CCK-8 (Shanghai Shenggong Biology Engineering Technology Service) was used to evaluate cell proliferation. BC cells were seeded in 96-well plates at a density of $1 \times 10^{5}$ cells per $200 \mu \mathrm{l}$ for $24 \mathrm{~h}$, followed by the addition of a total of $10 \mu \mathrm{l} \mathrm{CCK}-8$ solution into each well of the plate and incubation for $2 \mathrm{~h}$ at $37^{\circ} \mathrm{C}$, following which absorbance at $450 \mathrm{~nm}$ was measured for each well using a microplate reader. A fixed time point was set up for detection every day.

Transwell assay. Matrigel (100 $\mu \mathrm{l})$ was spread on the upper surface of the Transwell chamber filter and incubated at $37^{\circ} \mathrm{C}$ for $30 \mathrm{~min}$ to allow polymerization. A total of $500 \mu \mathrm{l}$ complete medium containing $10 \%$ FBS was added to a 24 -well plate, and the Transwell chamber was inserted. MDA-MB-231 cells $\left(1 \times 10^{6} / \mathrm{ml}\right)$ were suspended in $200 \mu \mathrm{l}$ serum-free DMEM and added to the upper chamber. Following 48-h incubation, the cells were fixed with $100 \%$ methanol for $15 \mathrm{~min}$ at room temperature and stained with $0.2 \%$ crystal violet and incubated for $10 \mathrm{~min}$ at room temperature. The number of invasive cells was counted under an inverted TS2R-FL microscope (Magnification, x40; Nikon Corporation).
Construction of pcDNA3.1-WT and pcDNA3.1-Radixin overexpression vectors. The microRNA.org web prediction software (http://www.microrna.org/microrna/home.do) was used to predict the target of miR-200b. According to the requirements of lentiviral packaging, the radixin sequence was inserted in the front of the cPPT/CTS site, and the linearization of the vector was achieved through SwaI or PacI single digestion. The overlapping sequence size was 15-20 bp excluding the restriction site. Using $\mathrm{PacI}$ single enzyme digestion as an example, the upstream and downstream primers of radixin gene were designed as follows: pcDNA3.1-WT forward, 5'-TCTGCCATAGCAAAACAAG-3' and reverse, 5'-CTG GTCGAGCTGGACGGCGACG-3'; and pcDNA3.1-radixin forward, 5'-TCTGCCATAGCAAAACAAGC-3' and reverse, 5'-CTGGTCGAGCTGGACGGCGACG-3'. The radixin gene was amplified by PCR $\left(94^{\circ} \mathrm{C}\right.$ for $1 \mathrm{~min}, 35$ cycles of $94^{\circ} \mathrm{C}$ for $15 \mathrm{sec}, 55^{\circ} \mathrm{C}$ for $20 \mathrm{sec}$ and $72^{\circ} \mathrm{C}$ for $30 \mathrm{sec}$, before $72^{\circ} \mathrm{C}$ for 1 min), which was ligated into the vector using the $\mathrm{NEB}^{\circledR}$ PCR Cloning Kit (New England BioLabs, Inc.) according to the manufacturer's protocols. A single clone was selected and verified to produce a positive clone. After the plasmid was successfully constructed, the $293 \mathrm{~T}$ cells were transfected for $24 \mathrm{~h}$ at $37^{\circ} \mathrm{C}$ using Lipofectamine ${ }^{\circledR} 2000$ (Thermo Fisher Scientific, Inc.) followed by analysis; if stable expression was achieved, the recombinant plasmid was used to package the lentivirus using High-titer, one-step lentivirus packaging systems (Lenti-X ${ }^{\mathrm{TM}}$ Packaging Single Shots; cat. no. 631278; Takara Bio, Inc.) according to the manufacturer's protocols.

Colony formation experiments. Cells $\left(1 \times 10^{4}\right)$ in logarithmic growth phase were seeded onto $6 \mathrm{~cm}$ plates and cultured for 2-3 weeks. On appearance of visible colonies cells were washed twice with PBS, fixed in $100 \%$ methanol for $15 \mathrm{~min}$ at room temperature, stained with $0.2 \%$ crystal violet for $20 \mathrm{~min}$ at room temperature and air-dried after further rinsing with water. The number of visible colonies was counted in five random fields under an inverted light microscope (magnification, x40; IX51; Olympus Corporation) using a transparent film with grids.

Wound healing assay. MDA-MB-231 cells ( $1 \times 10^{4}$ cells/well) were inoculated into six-well plates and cultured routinely until $\sim 70-80 \%$ confluence was reached following which scratches were introduced using a $200 \mu \mathrm{l}$ sterile pipette tip. The cells were washed three times with sterile PBS to remove the cells from the scratched region and were then cultured in serum-free culture medium at $37^{\circ} \mathrm{C}$ with $5 \% \mathrm{CO}_{2}$. Images of the cells were captured at 0 and $48 \mathrm{~h}$ following wound introduction under an inverted light microscope (magnification, $\mathrm{x} 40$; IX51; Olympus Corporation). The following formula was used to calculate cell migration: Cell migration distance $=$ distance at $0 \mathrm{~h}$-distance at $48 \mathrm{~h}$.

Statistical analysis. SPSS 18.0 software was used for data analysis. Data are presented as the mean \pm standard deviation and were compared by one-way ANOVA followed by Bonferroni post hoc test. The correlation between miR-200b and radixin mRNA expression levels in BC tissue was analyzed by Spearman's rank test. $\mathrm{P}<0.05$ was considered to indicate a statistically significant difference. 


\section{Results}

Regulatory relationship between $\mathrm{miR}-200 \mathrm{~b}$ and radixin. Bioinformatics analysis identified a potential complementary binding site for miR-200b in the 3'-UTR of radixin mRNA (Fig. 1A). Dual luciferase reporter assay results demonstrated that miR-200b mimic or inhibitor transfection significantly reduced or enhanced the relative luciferase activity in 293T cells, respectively, which suggested that radixin was the target gene of miR-200b (Fig. 1B).

miR-220b expression is downregulated, whereas radixin level is elevated in BC tissue. RT-qPCR analysis demonstrated that the expression of radixin mRNA was significantly increased in patients with $\mathrm{BC}$ compared with the control group; the levels increased with TNM stage (Fig. 2A). By contrast, the expression levels of miR-200b were reduced in BC tissue compared with those in the control group and higher compared with lower TNM stages (Fig. 2B). Spearman's rank correlation analysis revealed that a significant moderate negative correlation between miR-200b and radixin mRNA expression levels in $\mathrm{BC}$ tissues ( $\mathrm{r}=-0.693$; $\mathrm{P}<0.001$; Fig. 2C).

miR-220b and radixin expression levels are associated with $B C$ cell metastasis. RT-qPCR analysis demonstrated that the expression of radixin mRNA in BC cells was significantly higher compared with that in normal breast MCF-10A cells; it was also higher in the highly metastatic MDA-MB-231 cells compared with that in the moderately metastatic MCF-7 cells (Fig. 3A). miR-200b expression was reduced in MDA-MB-231 cells compared with that in MCF-7 and MCF-10A cells (Fig. 3B). Western blotting revealed that the protein expression levels of radixin in BC cells were higher compared with those in normal breast cells MCF-10A. In addition, the protein expression levels of radixin in the highly metastatic MDA-MB-231 cells was higher compared with that in MCF-7 cells (Fig. 3C and D).

miR-200b overexpression reduces radixin expression and cell invasion. RT-qPCR analysis demonstrated that transfection with the miR-200b mimic significantly increased miR-200b expression; whilst transfection with the miR-200b mimic or siRNA-radixin significantly reduced the expression of radixin mRNA in MDA-MB-231 cells (Fig. 4A and B). Western blotting revealed that compared with the miR-NC group, the protein expression of radixin in MDA-MB-231 cells was downregulated in the miR-200b mimic group; the amount of intracellular radixin protein was significantly lower in the siRNA-radixin group compared with that in the siRNA-NC group (Fig. 4C). Transwell assay demonstrated that transfection with the miR-200b mimic or siRNA-radixin significantly reduced the invasive ability of MDA-MB-231 cells (Fig. 4D and E).

pcDNA3.1-radixin overexpression vector increases cell proliferation and invasion. The radixin overexpression vector was constructed and verified by PCR. The pcDNA3.1-WT was amplified by PCR to obtain a fragment with a size of $1,771 \mathrm{bp}$. The pcDNA3.1-radixin overexpression vector was also amplified by PCR to obtain a fragment with a size of $1,771 \mathrm{bp}$.
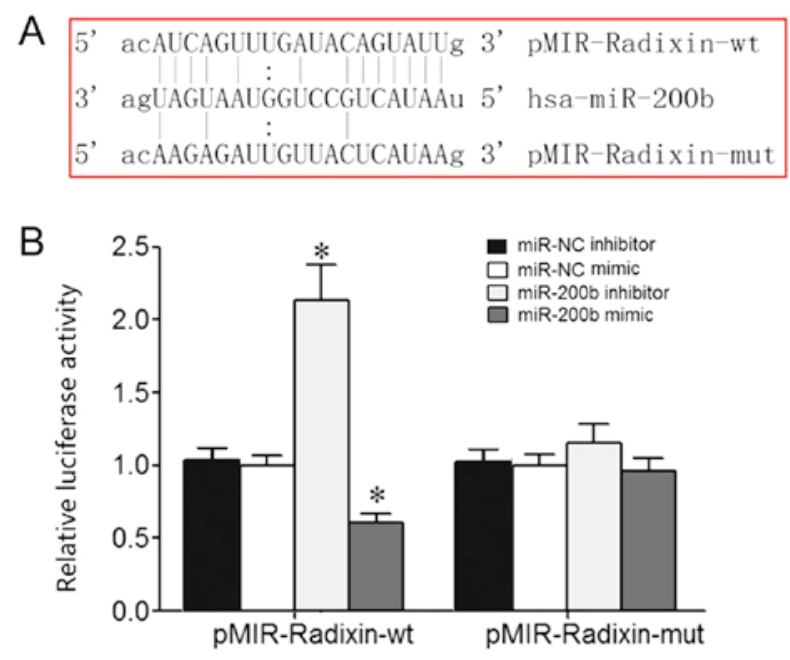

Figure 1. miR-200b directly interacts with radixin. (A) Complementary binding site of miR-200b in the 3'-untranslated region of radixin mRNA. (B) Dual luciferase reporter assay results. ${ }^{*} \mathrm{P}<0.05$ vs. miR-NC. miR, microRNA; NC, negative control; wt, wild-type; mut, mutant.

The expression of Radixin and miR-200b was analyzed by RT-qPCR using the radixin overexpression vector (Fig. 5A). RT-qPCR analysis showed that the expression of radixin was significantly increased following pcDNA3.1-radixin overexpression compared with cells transfected with pcDNA3.1-WT (Fig. 5B). Radixin overexpression significantly promoted cell proliferation (Fig. 5C and D), migration (Fig. 5E) and invasion (Fig. 5F).

miR-200b overexpression inhibits $B C$ cell proliferation. The results of the EdU staining revealed that the EdU-positive staining rate in MDA-MB-231 cells transfected with the miR-200b mimic was lower compared with that in cells transfected with the miR-NC (Fig. 5A and B). The EdU-positive staining rate in the siRNA-radixin group was significantly lower compared with that of the siRNA-NC group (Fig. 6A and B). However, transfection with the miR-200b inhibitor increased cell proliferation (Fig. 6C) and invasion (Fig. 6D).

\section{Discussion}

The ERM family comprises ezrin, radixin and moesin, which exist in the microvilli and adherens junctions $(24,25)$. ERM proteins connect the cytoskeleton and the cell membrane through the ERM domain and participate in cell morphogenesis, migration, differentiation, adhesion and other functions $(24,25)$. Radixin is predominantly involved in physiological processes, including intercellular adhesion, signal transduction and cell movement (26). Abnormal changes in radixin expression can cause the occurrence of a number of diseases and may participate in the occurrence and progression of tumors by regulating tumor-related signaling pathways. For example, Bartholow et al (27) demonstrated that the expression of radixin in prostate cancer tissues was significantly lower compared with that of benign prostatic hyperplasia and normal prostate tissues, which suggested that radixin may be involved in the development of prostate cancer. Chen et al (28) found altered radixin expression in 

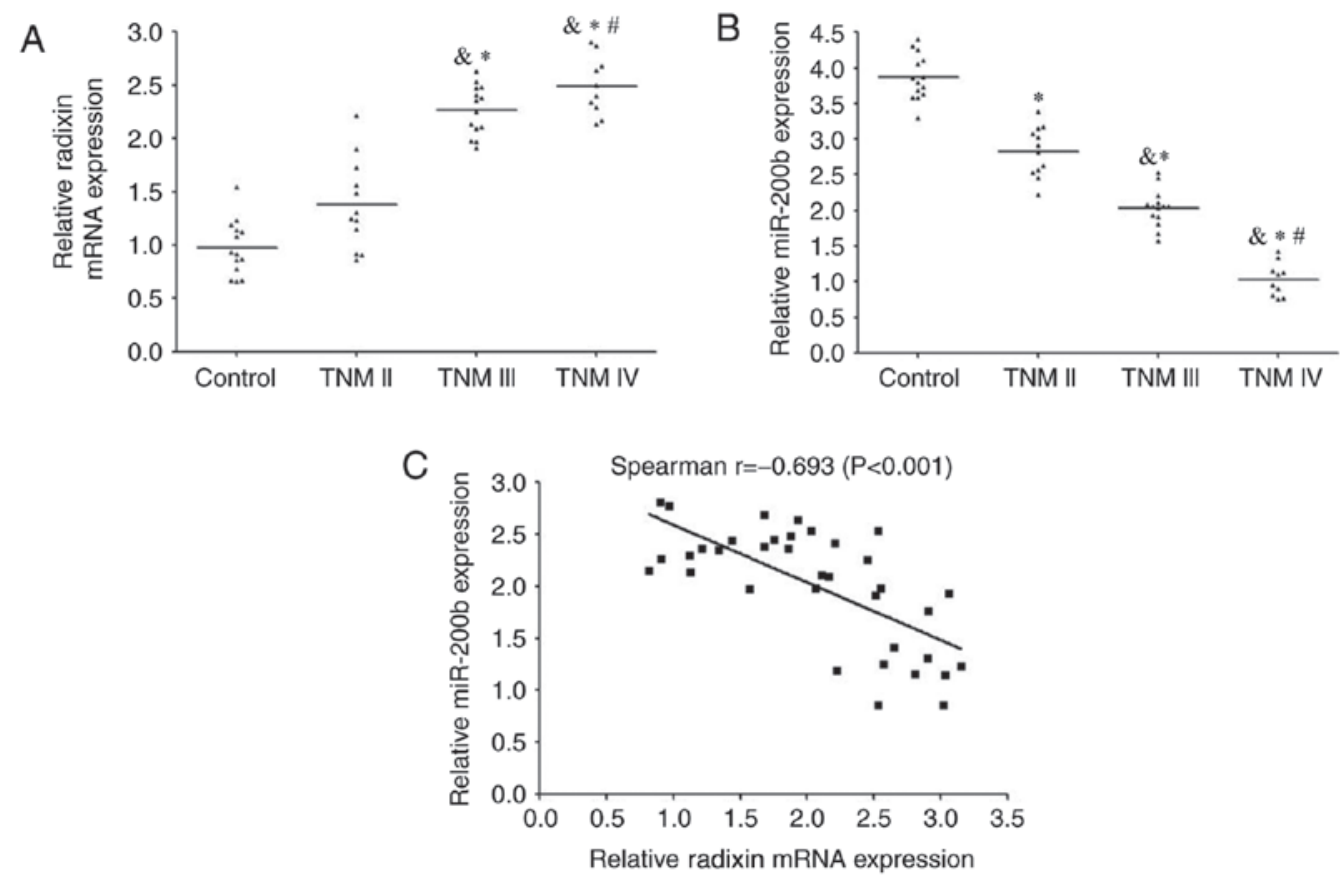

Figure 2. miR-220b expression is downregulated, whereas radixin expression is upregulated in breast cancer tissue. (A) Radixin mRNA expression in breast cancer tissues was detected by RT-qPCR. (B) miR-200b expression in breast cancer tissues was detected by RT-qPCR. (C) Spearman's rank correlation analysis between miR-200b and radixin expression levels. ${ }^{*} \mathrm{P}<0.05$ vs. control; ${ }^{\circledR} \mathrm{P}<0.05$ vs. TNMII; ${ }^{\text {}} \mathrm{P}<0.05$ vs. TNMIII. miR, microRNA; TNM, Tumor-Node-Metastasis; RT-qPCR, reverse transcription-quantitative PCR.

A

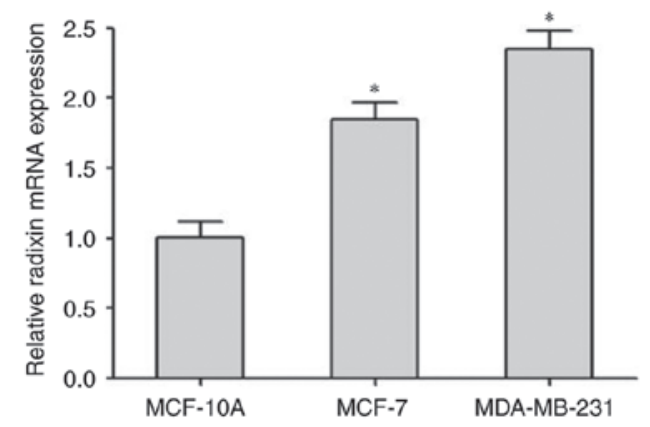

C

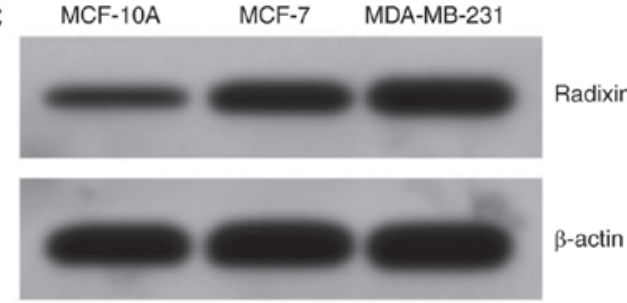

B
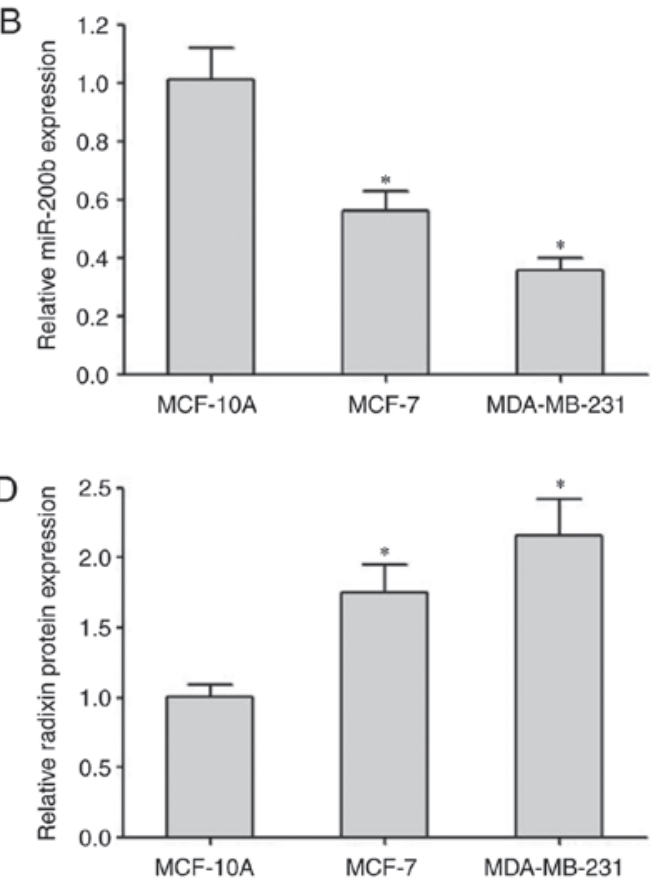

Figure 3. miR-220b downregulation and radixin upregulation are associated with breast cancer metastasis. (A) Radixin mRNA expression in normal breast cells and breast cancer cell lines was detected by RT-qPCR. (B) miR-200b expression in normal breast cells and breast cancer cell lines was detected by RT-qPCR. (C) Radixin protein expression detected by western blotting. (D) Radixin protein expression analysis in breast cancer cell lines. ${ }^{*}<0.05$ vs. MCF-10A. miR, microRNA; RT-qPCR, reverse transcription-quantitative PCR.

human glioma cells and implanted them into nude mice; the results revealed that knockdown of radixin inhibited tumor growth and invasion. The underlying molecular mechanism may involve the expression of thrombospondin 1, E-cadherin, matrix metallopeptidase 9 and other metastasis-inducing factors (22). Zhu et al (15) reported that silenced radixin expression in the gastric cancer cell line SGC-7901 upregulated the expression of E-cadherin through the NF-kB/Snail 

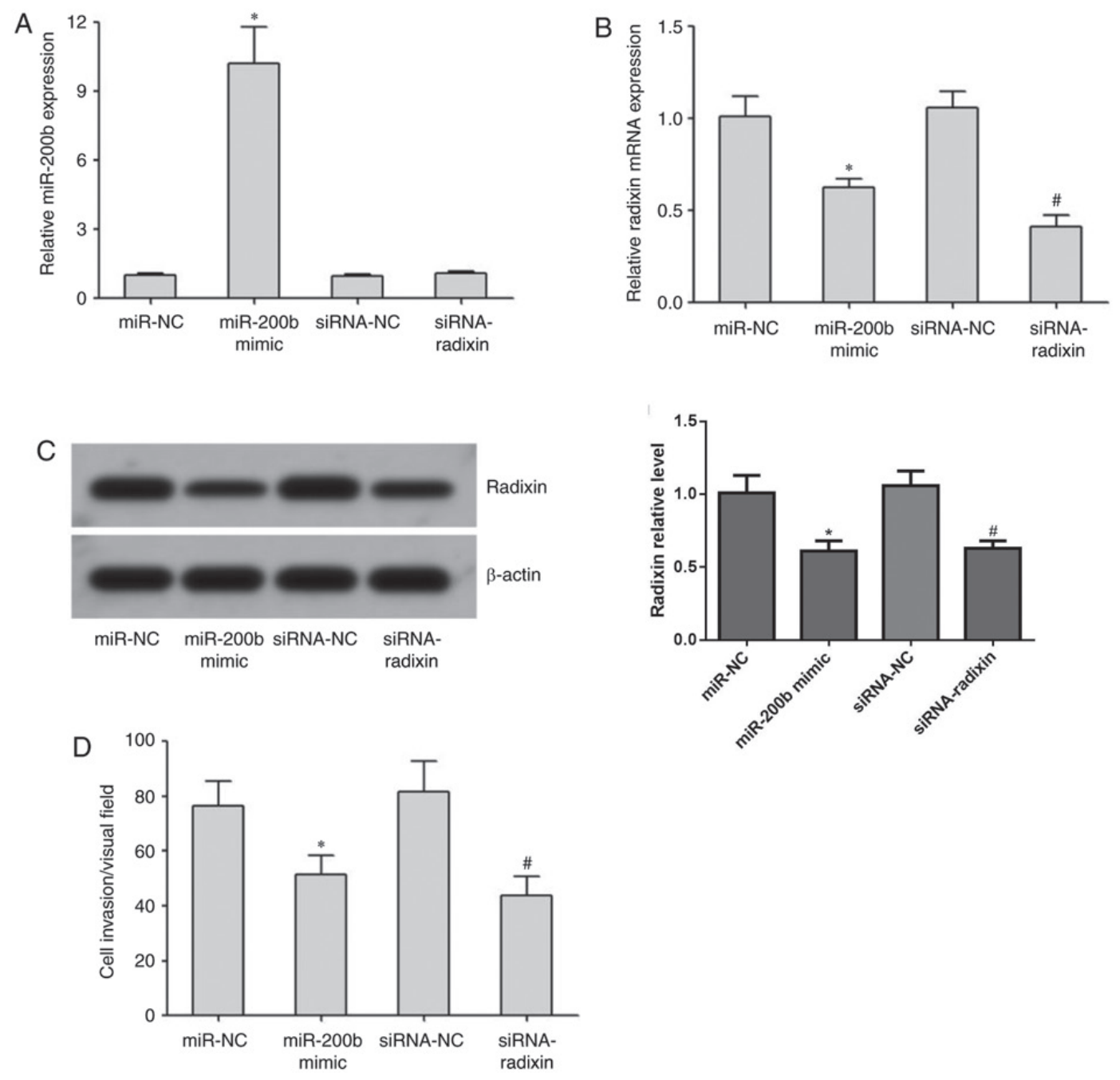

$\mathrm{E}$
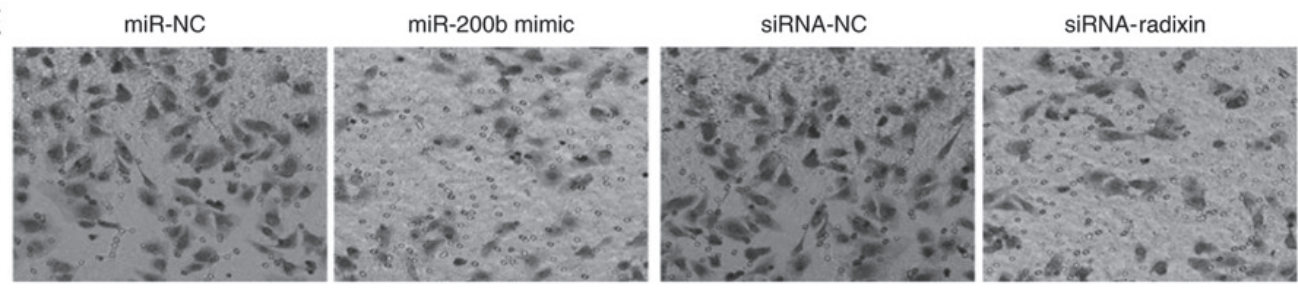

Figure 4. miR-200b overexpression reduces radixin expression and alleviates breast cancer cell invasion. (A) miR-200b expression was detected by RT-qPCR. (B) Radixin mRNA expression was detected by RT-qPCR. (C) Radixin protein expression was detected by western blotting. (D) Cell invasion was detected by Transwell assay. (E) Representative images of invasive cells in each condition. Magnification, $\mathrm{x} 40$. " $\mathrm{P}<0.05$ vs. miR-NC; ${ }^{\text {"P}} \mathrm{P}<0.05$ vs. siRNA-NC. miR, microRNA; siRNA, small interfering RNA; NC, negative control; RT-qPCR, reverse transcription-quantitative PCR.

pathway, thus inhibiting the metastasis of SGC-7901 cells. Chen et al (28) demonstrated that silencing radixin expression in pancreatic cancer cells significantly inhibited cell proliferation in vitro and tumorigenicity in vivo. Hua et al (29) reported that low expression of radixin was associated with an enhanced invasive ability of glioma cells. Knockdown of radixin expression inhibited the migration and invasion of glioma cells (30). miR-200b is associated with the development of various tumors, such as prostate (20), lung (21) and cervical (22) cancer. Bioinformatics analysis in the present study has identified a complementary binding site for miR-200b in the 3'-UTR of radixin mRNA. Therefore, the present study investigated the role of miR-200b in regulating radixin expression, cell proliferation and invasion in BC.

In the present study, the results of the dual luciferase gene reporter assay demonstrated that the miR-200b mimic significantly reduced the relative luciferase activity in 293T cells, whereas the miR-200b inhibitor enhanced the luciferase activity. However, the miR-200b mimic and inhibitor exhibited no significant effects on the relative luciferase activity in 293T cells transfected with pMIR-Radixin-mut, indicating that miR-200b directly targeted the 3'-UTR of radixin mRNA. The expression of miR-200b was significantly decreased, whereas the expression of Radixin was increased in patients 

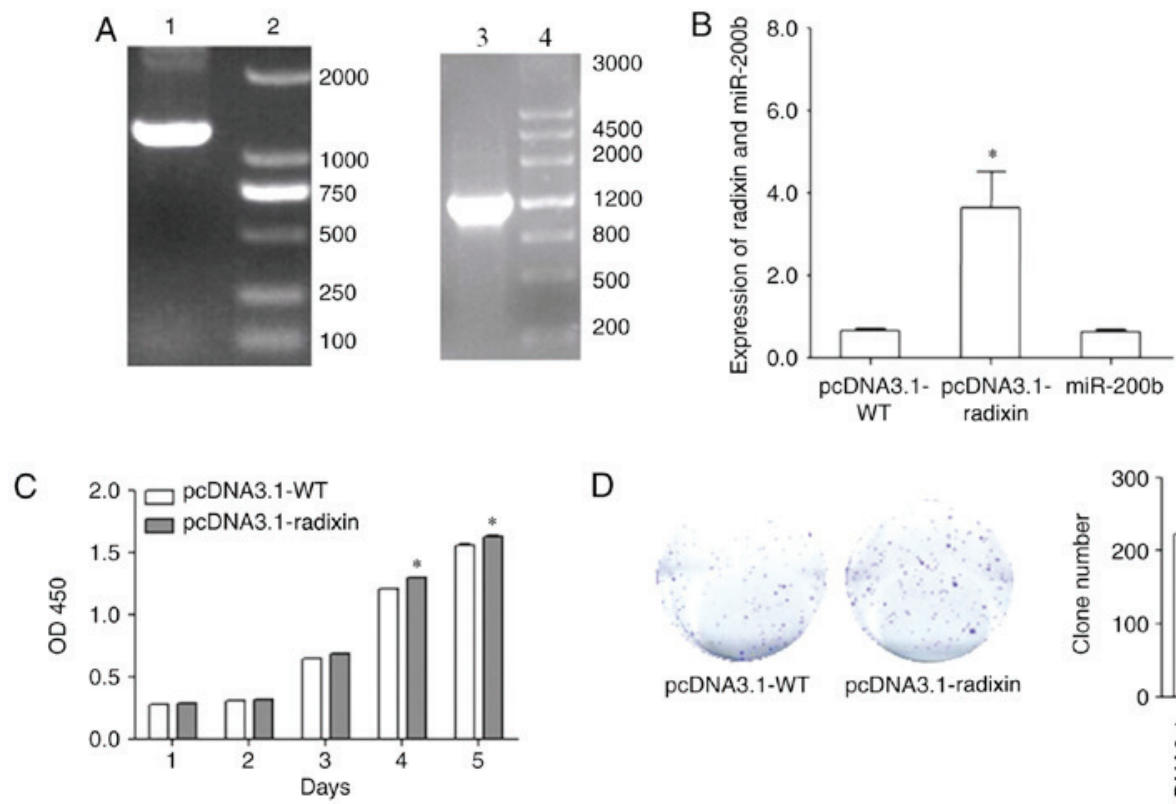

D
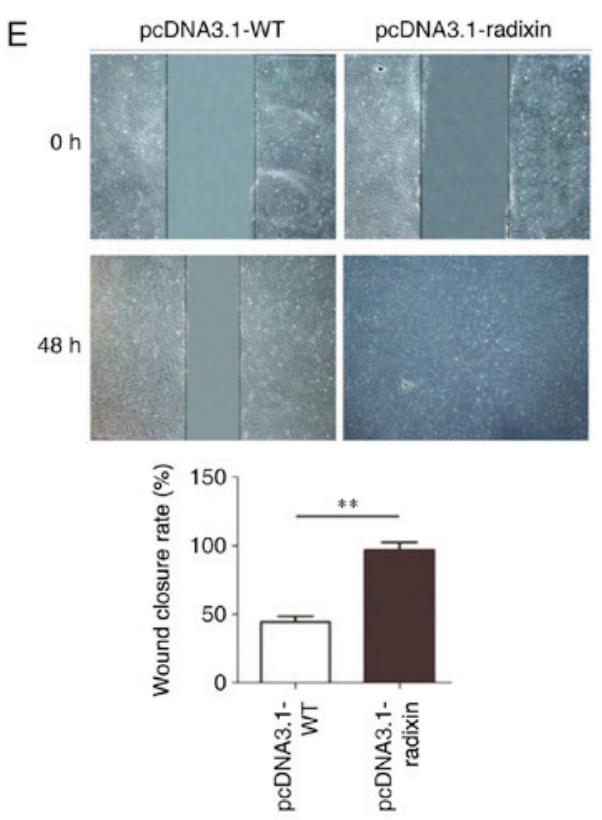

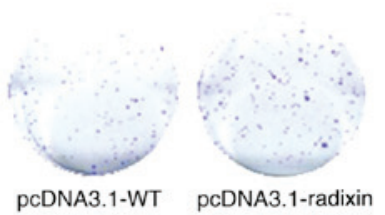

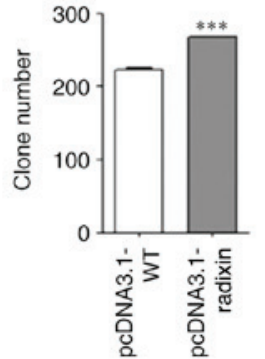

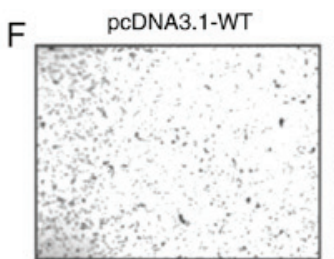

pcDNA3.1-radixin
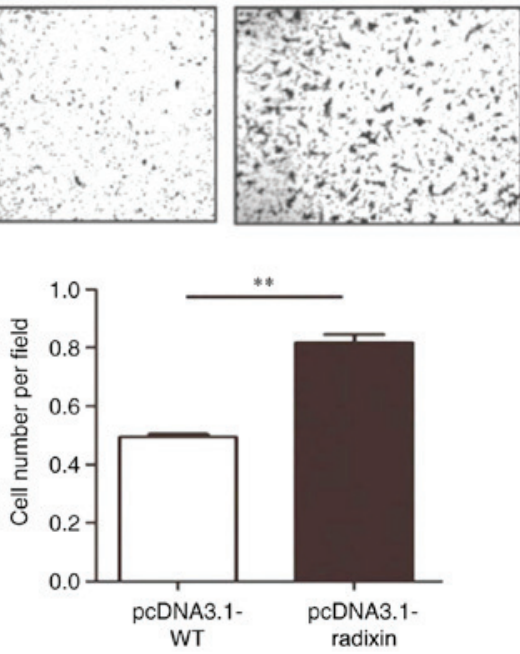

Figure 5. Radixin overexpression increases breast cancer cell proliferation and invasion. (A) PCR verification of pcDNA3.1-radixin overexpression. Each lane was labelled as follows: 1, pcDNA3.1-WT; 2, Marker; 3, pcDNA3.1-radixin overexpression; and 4, Marker. (B) Expression of radixin and miR-200b in cells transfected with radixin or miR-200b overexpression vectors. (C) Cell Counting Kit-8 assay analysis of cell proliferation. (D) Cloning assay analysis of single cell proliferation. (E) Wound-healing assay was performed to analyze cell migration. (F) Transwell assay was performed to analyze cell invasion (magnification: $\mathrm{x} 40) .{ }^{*} \mathrm{P}<0.05,{ }^{* *} \mathrm{P}<0.01,{ }^{* * *} \mathrm{P}<0.001$ vs. pcDNA3.1-WT. miR, microRNA; WT, wild-type; OD, optical density.

with BC compared with the control group, and the levels were associated with the TNM stage. In addition, radixin expression was increased, whereas miR-200b expression was reduced in $\mathrm{BC}$ cell lines compared with normal breast cells, which was related to cell invasiveness. Li et al (31) demonstrated that the expression of miR-200b was significantly decreased in the highly invasive MDA-MB-231 cells compared with the moderately invasive MCF-7 cells. Yang et al (32) reported that decreased expression of miR-200b was associated with drug resistance and epithelial-mesenchymal transition (EMT) in BC MCF-7 cells, suggesting that miR-200b downregulation was associated with the enhancement of invasive characteristics in BC. Yao et al (33) demonstrated that compared with the normal breast epithelial HBL-10 cells, the expression levels of miR-200b in BC MDA-MB-231, SK-BR-3 and MDA-MB-468 cells were significantly reduced. Compared with normal breast tissue, the expression of miR-200b in BC tissue was also reduced, and was associated with TNM stage (33). In addition, miR-200b has been reported to participate in BC cell migration and invasion by regulating ERM in MCF-7 and MDA-MB-231 (34). The results of these studies suggested that miR-200b may serve a regulatory role in the pathogenesis and progression of $\mathrm{BC}$.

In the present study, overexpression of miR-200b or knockdown of radixin significantly alleviated the invasive ability of $\mathrm{BC}$ cells and inhibited cell proliferation. Humphries et al (35) 

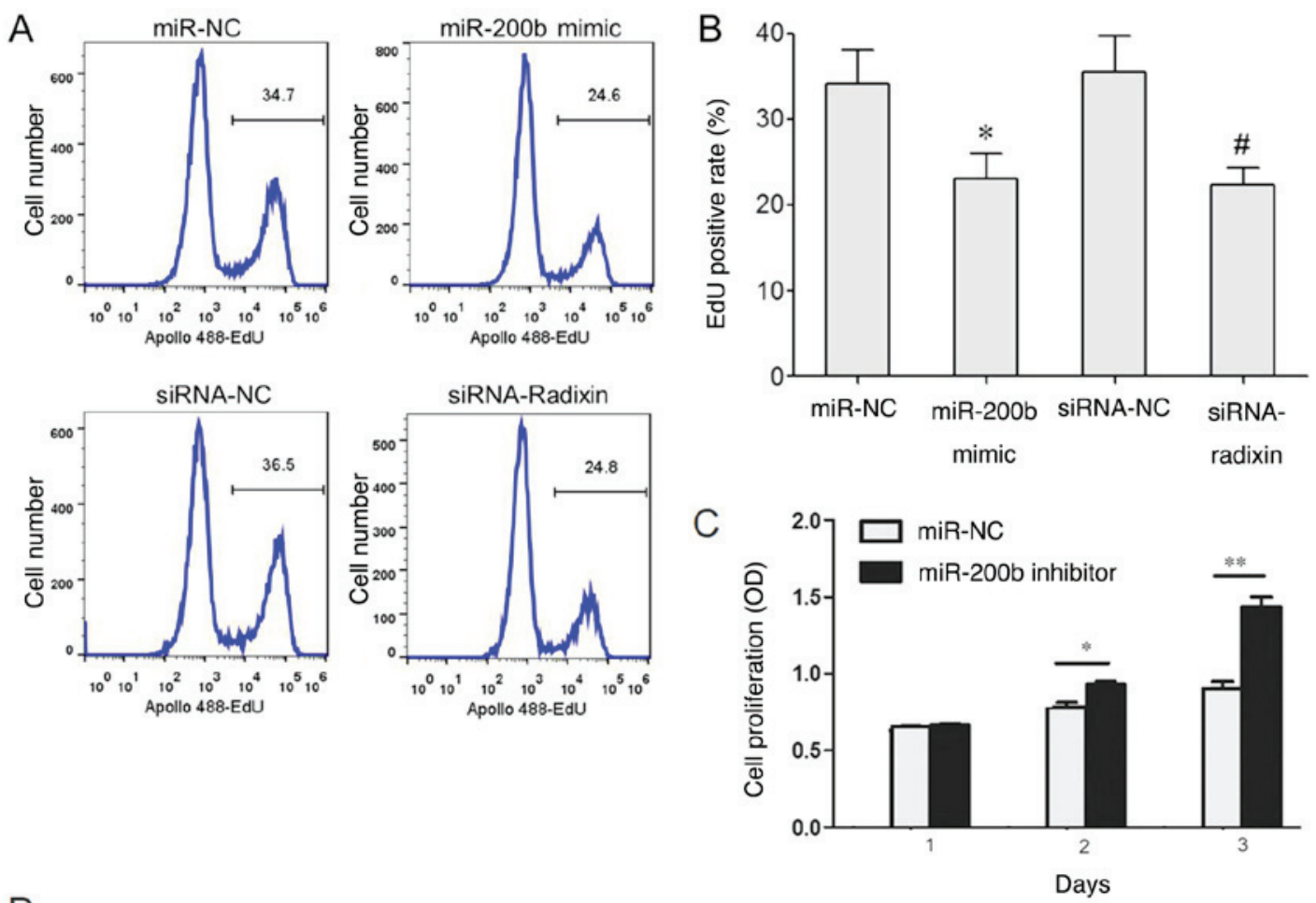

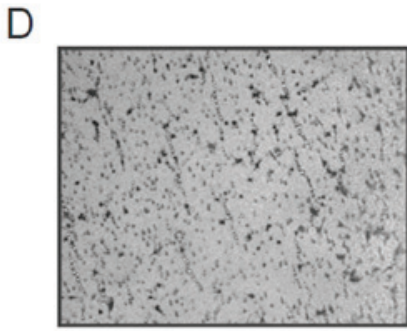

miR-NC

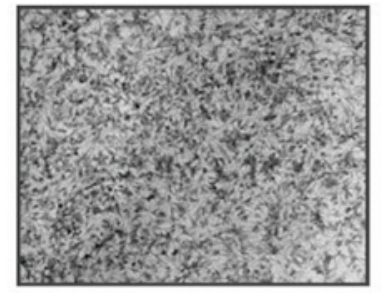

miR-200b inhibitor

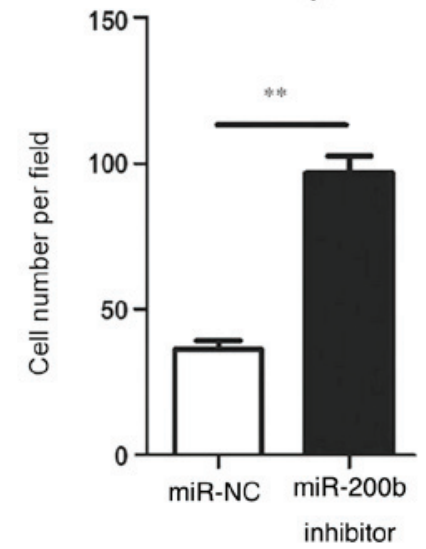

Figure 6. miR-200b overexpression inhibits breast cancer cell proliferation. (A) Cell proliferation was detected by EdU staining. (B) EdU positive rate analysis (C) Cell proliferation following transfection with the miR-200b inhibitor. (D) Cell invasion following transfection with the miR-200b inhibitor. Magnification, $\mathrm{x} 40 .{ }^{*} \mathrm{P}<0.05,{ }^{* *} \mathrm{P}<0.01$ vs. miR-NC; "P $<0.05$ vs. siRNA-NC. miR, microRNA; EdU, 5-ethynyl-2'-deoxyuridine; NC, negative control; siRNA, small interfering RNA; OD, optical density.

demonstrated that overexpression of miR-200b in BC cells can inhibit the expression of its target gene ARHGAP18 to suppress the migration and invasion of BC cells. Li et al (31) demonstrated that overexpressed miR-200b in MDA-MB-231 cells alleviated the proliferation, migration and invasion of MDA-MB-231 cells through targeted inhibition of LIM domain kinase 1 gene expression, indicating the tumor suppressor role of miR-200b in BC. Yang et al (32) reported that overexpression of miR-200b inhibited the expression of fibronectin 1 gene, reduced the drug resistance and EMT process, restrained cell migration and proliferation and weakened the invasive ability of MCF-7 cells. Yao et al (33) reported that overexpression of miR-200b induced apoptosis and reduced proliferation of BC cells. Ye et al (36) also revealed that the expression levels of miR-200b in BC tissues and cells were abnormally decreased, whereas increased miR-200b expression significantly inhibited proliferation, reduced cell invasive ability and decreased malignant characteristics. Zheng et al (37) demonstrated in xenograft studies that low expression of miR-200b was associated with $\mathrm{BC}$; overexpression of miR-200b inhibited fucosyltransferase 4 and reduced the clone formation, migration, invasion, tumorigenicity and lung metastasis of breast cancer MCF-7 and MDA-MB-231 cells. In the present study, miR-200b enhancement suppressed BC cell proliferation and invasion, which was consistent with the previous reports. Valastyan et al (38) reported that overexpression of radixin significantly promoted the invasion and metastasis of $\mathrm{BC}$ cells. Knockdown of radixin by siRNA reduced the invasion of $\mathrm{BC}$ cells (38), suggesting that radixin may serve a role in the regulation of $\mathrm{BC}$ cell invasion. The present study revealed that low miR-200b expression may serve a role in upregulating radixin and promoting the development of breast cancer. Overexpression of miR-200b inhibited 
the expression of radixin and reduced the proliferation and invasion of breast cancer cells. However, the mechanism by which radixin affects the proliferation and invasion of breast cancer cells has not been elucidated.

In conclusion, low miR-200b and high radixin expression levels may be associated with increased cell invasion in BC. miR-200b overexpression inhibited BC cell proliferation and invasion by targeting radixin expression.

\section{Acknowledgments}

Not applicable.

\section{Funding}

This work was supported by The Nantong City Social Development Fund (grant No. MS12017017-4).

\section{Availability of data and materials}

All data generated or analyzed during this study are included in this published article.

\section{Authors' contributions}

JY, CX, HL and HY performed the majority of the experiments and analyzed the data. $\mathrm{HH}, \mathrm{CG}$ and $\mathrm{ZW}$ performed the cell transfection, cell proliferation and invasion assays in addition to analyzing the data. CX and HY designed the study and wrote the manuscript.

\section{Ethics approval and consent to participate}

This study was approved by the Research Ethics Committee of Nantong Traditional Chinese Medicine Hospital (Nantong, China), and all patients provided written informed consent prior to the study.

\section{Patient consent for publication}

Not applicable.

\section{Competing interests}

The authors declare that they have no competing interests.

\section{References}

1. Winters S, Martin C, Murphy D and Shokar NK: Breast cancer epidemiology, prevention, and screening. Prog Mol Biol Transl Sci 151: 1-32, 2017.

2. Fraser VJ, Nickel KB, Fox IK, Margenthaler JA and Olsen MA: The epidemiology and outcomes of breast cancer surgery. Trans Am Clin Climatol Assoc 127: 46-58, 2016.

3. Rojas K and Stuckey A: Breast cancer epidemiology and risk factors. Clin Obstet Gynecol 59: 651-672, 2016.

4. Sung H, Ren J, Li J, Pfeiffer RM, Wang Y, Guida JL, Fang Y, Shi J, Zhang K and Li N: Breast cancer risk factors and mammographic density among high-risk women in urban China. NPJ Breast Cancer 4: 3, 2018.

5. Li T, Tang L, Gandomkar Z, Heard R, Mello-Thoms C, Shao Z and Brennan P: Mammographic density and other risk factors for breast cancer among women in China. Breast J 24: 426-428, 2018 .
6. Zuo TT, Zheng RS, Zeng HM, Zhang SW and Chen WQ: Female breast cancer incidence and mortality in China, 2013. Thorac Cancer 8: 214-218, 2017.

7. Lee EY and Muller WJ: Oncogenes and tumor suppressor genes. Cold Spring Harb Perspect Biol 2: a003236, 2010.

8. Wang LH, Wu CF, Rajasekaran N and Shin YK: Loss of tumor suppressor gene function in human cancer: An overview. Cell Physiol Biochem 51: 2647-2693, 2018.

9. Asp N, Kvalvaag A, Sandvig K and Pust S: Regulation of ErbB2 localization and function in breast cancer cells by ERM proteins. Oncotarget 7: 25443-25460, 2016.

10. Pokharel D, Padula MP, Lu JF, Jaiswal R, Djordjevic SP and Bebawy M: The role of CD44 and ERM proteins in expression and functionality of P-glycoprotein in breast cancer cells. Molecules 21: 290, 2016.

11. Clucas $J$ and Valderrama F: ERM proteins in cancer progression. J Cell Sci 127: 267-275, 2014.

12. Montt-Guevara MM, Shortrede JE, Giretti MS, Giannini A, Mannella P, Russo E, Genazzani AD and Simoncini T: Androgens regulate T47D cells motility and invasion through actin cytoskeleton remodeling. Front Endocrinol (Lausanne) 7: $136,2016$.

13. Fernando H, Martin TA, Douglas-Jones A, Kynaston HG, Mansel RE and Jiang WG: Expression of the ERM family members (ezrin, radixin and moesin) in breast cancer. Exp Ther Med 1: 153-160, 2010.

14. Tsai MM, Wang CS, Tsai CY, Chen CY, Chi HC, Tseng YH, Chung PJ, Lin YH, Chung IH, Chen CY and Lin KH: MicroRNA-196a/-196b promote cell metastasis via negative regulation of radixin in human gastric cancer. Cancer Lett 351: 222-231, 2014.

15. Zhu YW, Yan JK, Li JJ, Ou YM and Yang Q: Knockdown of radixin suppresses gastric cancer metastasis in vitro by up-regulation of E-Cadherin via NF- $\mathrm{B} /$ Snail pathway. Cell Physiol Biochem 39: 2509-2521, 2016.

16. He J, Zhao J, Zhu W, Qi D, Wang L, Sun J, Wang B, Ma X, Dai Q and $\mathrm{Yu}$ X: MicroRNA biogenesis pathway genes polymorphisms and cancer risk: A systematic review and meta-analysis. PeerJ 4: e2706, 2016.

17. Shrestha S, Hsu SD, Huang WY, Huang HY, Chen W, Weng SL and Huang HD: A systematic review of microRNA expression profiling studies in human gastric cancer. Cancer Med 3: 878-888, 2014.

18. Catto JW, Alcaraz A, Bjartell AS, De Vere White R, Evans CP, Fussel S, Hamdy FC, Kallioniemi O, Mengual L, Schlomm T and Visakorpi T: MicroRNA in prostate, bladder, and kidney cancer: A systematic review. Eur Urol 59: 671-681, 2011.

19. Li X, Abdel-Mageed AB, Mondal D and Kandil E: MicroRNA expression profiles in differentiated thyroid cancer, a review. Int J Clin Exp Med 6: 74-80, 2013.

20. Janiak M, Paskal W, Rak B, Garbicz F, Jarema R, Sikora K and Włodarski P: TIMP4 expression is regulated by miR-200b-3p in prostate cancer cells. APMIS 125: 101-105, 2017.

21. Xiao P, Liu W and Zhou H: miR-200b inhibits migration and invasion in non-small cell lung cancer cells via targeting FSCN1. Mol Med Rep 14: 1835-1840, 2016.

22. Zeng F, Xue M, Xiao T, Li Y, Xiao S, Jiang B and Ren C: MiR-200b promotes the cell proliferation and metastasis of cervical cancer by inhibiting FOXG1 Biomed Pharmacother 79: 294-301, 2016.

23. Livak KJ and Schmittgen TD: Analysis of relative gene expression data using real-time quantitative PCR and the 2(-Delta Delta C(T)) method. Methods 25: 402-408, 2001.

24. Arpin M, Chirivino D, Naba A and Zwaenepoel I: Emerging role for ERM proteins in cell adhesion and migration. Cell Adh Migr 5: 199-206, 2011

25. Fehon RG, McClatchey AI and Bretscher A: Organizing the cell cortex: The role of ERM proteins. Nat Rev Mol Cell Biol 11: 276-287, 2010.

26. Ivetic A and Ridley AJ: Ezrin/radixin/moesin proteins and Rho GTPase signalling in leucocytes. Immunology 112: 165-176, 2004.

27. Bartholow TL, Chandran UR, Becich MJ and Parwani AV: Immunohistochemical staining of radixin and moesin in prostatic adenocarcinoma. BMC Clin Pathol 11: 1, 2011.

28. Chen SD, Song MM, Zhong ZQ, Li N, Wang PL, Cheng S, Bai RX and Yuan H: Knockdown of radixin by RNA interference suppresses the growth of human pancreatic cancer cells in vitro and in vivo. Asian Pac J Cancer Prev 13: 753-759, 2012 . 
29. Hua D, Ding D, Han X, Zhang W, Zhao N, Foltz G, Lan Q, Huang $Q$ and Lin B: Human miR-31 targets radixin and inhibits migration and invasion of glioma cells. Oncol Rep 27: 700-706, 2012.

30. Qin JJ, Wang JM, Du J, Zeng C, Han W, Li ZD, Xie J and Li GL: Radixin knockdown by RNA interference suppresses human glioblastoma cell growth in vitro and in vivo. Asian Pac J Cancer Prev 15: 9805-9812, 2014.

31. Li D, Wang H, Song H, Xu H, Zhao B, Wu C, Hu J, Wu T, Xie D, Zhao J, et al: The microRNAs miR-200b-3p and miR-429-5p target the LIMK1/CFL1 pathway to inhibit growth and motility of breast cancer cells. Oncotarget 8: 85276-85289, 2017.

32. Yang X, Hu Q, Hu LX, Lin XR, Liu JQ, Lin X, Dinglin XX, Zeng JY, Hu H, Luo ML and Yao HR: miR-200b regulates epithelial-mesenchymal transition of chemo-resistant breast cancer cells by targeting FN1. Discov Med 24: 75-85, 2017.

33. Yao Y, Hu J, Shen Z, Yao R, Liu S, Li Y, Cong H, Wang X, Qiu W and Yue L: MiR-200b expression in breast cancer: A prognostic marker and act on cell proliferation and apoptosis by targeting Sp1. J Cell Mol Med 19: 760-769, 2015.
34. Hong H, Yu HZ, Yuan JF, Guo C, Cao H, Li W and Xiao C: MicroRNA-200b impacts breast cancer cell migration and invasion by regulating ezrin-radixin-moesin. Med Sci Monit 22: 1946-1952, 2016.

35. Humphries B, Wang Z, Li Y, Jhan JR, Jiang Y and Yang C: ARHGAP18 downregulation by miR-200b suppresses metastasis of triple-negative breast cancer by enhancing activation of RhoA. Cancer Res 77: 4051-4064, 2017.

36. Ye F, Tang H, Liu Q, Xie X, Wu M, Liu X, Chen B and Xie X: miR-200b as a prognostic factor in breast cancer targets multiple members of RAB family. J Transl Med 12: 17, 2014.

37. Zheng Q, Cui X, Zhang D, Yang Y, Yan X, Liu M, Niang B, Aziz F, Liu S, Yan Q and Liu J: miR-200b inhibits proliferation and metastasis of breast cancer by targeting fucosyltransferase IV and $\alpha 1,3$-fucosylated glycans. Oncogenesis 6: e358, 2017.

38. Valastyan S, Benaich N, Chang A, Reinhardt F and Weinberg RA: Concomitant suppression of three target genes can explain the impact of a microRNA on metastasis. Genes Dev 23: 2592-2597, 2009. 